\title{
The Impact of Service Quality on Customer Satisfaction in Commercial Bank of Ethiopia, Mekelle Branch
}

\author{
MebrahtomAbebeGebrehiwot \\ Bahir Dar University, College of Business and Economics, Management Department, Lecturer. \\ Ethiopia, AmharaProvince, Bahir Dar City, Bahir Dar University, Postal Codes =79, college of Business \\ Economics, building/office numbers $=$ Block 17, Room 305
}

\begin{abstract}
This paper examined the effect of service quality on customer satisfaction in Commercial Bank of Ethiopia, Mekelle branch. The five hypotheses were tested by using statistical techniques. The study is explanatory type of research. The sample size is 300 and is chosen on convenient basis. The primary source of data was collected using questionnaire. Data were analyzed by using SPSS version 21. Ordinal regression method was used to model the relationship between the customer satisfaction and service quality dimensions. The explanatory variables include tangibility, reliability, responsiveness, assurance and empathy; and the response variable is customer satisfaction. Customer satisfaction was measured on ordered, categorical, and five-point Likert scale: strongly disagree, disagree, neutral, agree and strongly agree. The model fitting statistics and the reliability of the model assumption: parallel lines tests, overall goodness of fit information were tested. The findings indicated that the explanatory variables were significantly associated with the customer satisfaction.
\end{abstract}

Keywords: Service quality dimensions and Customer satisfaction.

DOI: $10.7176 / \mathrm{JMCR} / 72-02$

Publication date:October $31^{\text {st }} 2020$

\section{Introduction}

Customers are the most important element for the existence and survival of business. Their satisfaction is important for realization of the business goals. Customer satisfaction is a vital element of banking strategy in today's increasingly competitive environment. Bank management must identify quality dimensions and improve service quality to satisfy customers. The banking sector is highly competitive, with banks not only competing among each other; but also with non-banks and other financial institutions (Kaynak \& Kucukemiroglu, 1992). Most bank product developments are easy to duplicate and when banks provide nearly identical services, they can only distinguish themselves on the basis of price and service quality delivery. Therefore, customer satisfaction is potentially an effective tool that banks can use to gain a competitive advantage and survive in today's everincreasing banking competitive environment.

In today's competitive business environment, commercial banks are competing with others in order to become the best banks and have maximum deposits and gain trust of customers in Ethiopia. The major factor that attracts the customers today is quality service. The banks that provide high quality service retain the existing customer and also pull the new customers towards their offices and branches. Therefore, banks launch new schemes and provide various quality services and facilities so as to retain and attract customers with different characteristics and businesses. Hence, this study explores service quality as a means for customer satisfaction.

Service quality has become ever more important to the achievement of customer satisfaction and competitive advantage and coupled with the increasing complexities of the need and expectation of customers, it is imperative to explore the relationship between service quality and customer satisfaction. So, the major objective of this study is to examine the level of customer satisfaction on the basis of service provided by the commercial bank of Ethiopia, Mekelle branch. The specific objectives are the following:

- To describe the mobility of customers to other banks.

- To describe service quality and customer satisfaction in commercial bank of Ethiopia.

- To measure the effect of service quality on customer satisfaction.

\section{Review of related Literature}

\subsection{Service Quality}

Currently, with increased competition, service quality has become a popular area for academic studies and has been recognized as a competitive advantage and supportive relationship with satisfied customers (Zeithmal, 2000). Quality of service has been defined as an overall evaluation done by the customer service (Eshghi et al, 2008). Perceived service quality in the banking industry is as a result of the gap between the expectation and the actual service provided. The initial SERVQUAL scale comprised of various marketing mix aspects however, price and promotion elements were not included (Bahia and Nantel, 2000). Mohamed \& Shirley (2009) emphasized that banks have be care about the quality of their services since this quality is considered the core of strategic competition. Walfried, et. al. (2000) characterized service as a set of characteristics that meet the clients' needs, 
enhancing the links between the organization and them, and improve the clients' esteem as well.

\subsection{Customer Satisfaction}

Customer satisfaction is portrayed as the result of a comparison of the customers' expectations and his or her consequent perceived performance of service quality (Herington \& Weaven, 2009). Customer satisfaction is basically a term most widely utilized in the trade and commerce industry. It is a business term clarifying about a measurement of the kind of products and services provided by a company to meet its customer's expectation. To some, this may be seen as the company's Key Performance Indicator. In a competitive marketplace where businesses compete for customers, customer satisfaction is seen as a key differentiator and increasingly has become a key element of business strategy.

Customer satisfaction is one of the critical perspectives of this research. It refers to serving people with their requirements and making them satisfy. It could be a person's feeling of delight of or dissatisfaction coming about from comparing a product's, perceived performance in relation to his or her expectations. In case the performance falls short of expectations, the customer is disappointed. If the performance matches the expectations, the customer is satisfied. If the performance exceeds the expectations, the customer highly satisfied or delighted (Kotler \& Keller, 2012). Papasolomou - Doukakis (2002) argued that the customer service which is a means of differentiation in competitive markets. In this way, it can utilize as a means of securing competitive advantage and permit the position of a company inside its industry. As far as it concerns the banks, they ought to constantly attempt to keep their customers due to high costs related to marketing campaigns.

\subsection{The relationship between service quality and customer satisfaction}

Fornell (1991) proposed that customer satisfaction is depending up on the most five service quality of service business. How service will be measured is certainly changing as the services provided become more complex and the nature of conveyance of the financial products change. However, one element appears unlikely to change and that is the feeling of satisfaction that is brought about as customers measure their expectations against their perceptions of actual performance (Spreng, et al, 1996). Kumar et al (2009) expressed that high quality of service will result in high customer satisfaction and improves customer loyalty. Zeithaml, et al (1985) cultivated a positive relationship between client satisfaction and service quality and widen the unique of special features of service products. They clarify that service in its production sense and consumption occurs simultaneously or is not separate. Brady and Robertson (2001) found service quality to be a predecessor of customer satisfaction for cognitivelyoriented consumers, and a consequence for emotional consumers. Bolton and Drew (1994) conclude that service quality is a primary input and customer satisfaction is the vital result or yield of it. In any case, taking their statement and dissect it one would ought to conclude that Bolton and Drew (1994) see this dynamic framework from the setting of service quality of the company building up the discernments required for the customer to get satisfaction from a particular service experience as dissimilar to pure service causing the customer to get satisfaction.

\subsection{Conceptual framework}

The independent variables of this study are service quality dimensions including tangibility, reliability, responsiveness, assurance, and empathy; and the dependent variable is customer satisfaction.

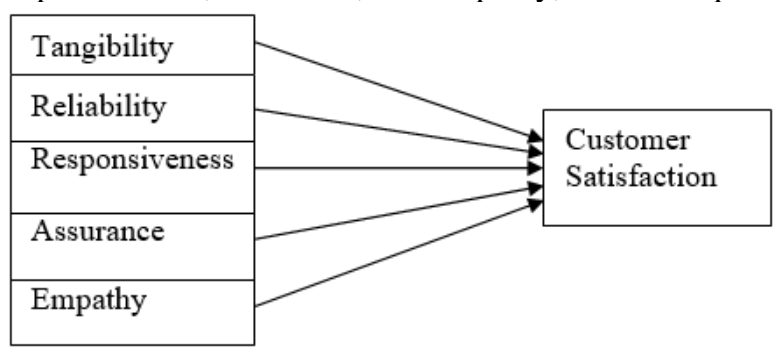

Figure 2.1: Conceptual framework

\subsection{Hypotheses development}

\subsubsection{Relationship between tangibility and Customer Satisfaction}

Siddiqui (2011) checked that customer satisfaction and tangibility are positively correlated with one another. This is positively illustrated in his research that bank clients usually look for tangible aspects which may be used as measures of service quality. Customers can assess the banks premises or appearance of the individuals of staff. The customer is satisfied with their services once their dread on their presumption and discernment towards the bank are met. Lai (2004) too strongly expressed that tangibility is positively related to client satisfaction.

H1: Tangibility has a significant positive effect on customer satisfaction. 


\subsubsection{Relationship between Reliability and Customer Satisfaction}

Reliability is defined as the ability to perform the necessary service to customers dependably; and accurately as promised to deliver (Zeithaml et al., 1990). Dealing whatever the problems in services faced by customers, performing the needed services right from the first time, services being rendered at the promised time and maintaining error-free record are the paradigm of reliability in terms of service quality which will strongly influence the level of customer satisfaction (Parasuraman et al., 1988). In banking services provided to the customer, accuracy in completing orders, maintaining precise record and quote, accuracy in billing, maintaining promised services are the basic views of reliability which is considered as the most important factor in convincing customers to retain in banking services (Yang and Fang, 2004). The above literature reviews will lead to the development of the following hypothesis:

H2: Reliability will have a significant impact on Customer Satisfaction.

\subsubsection{Relationship between Responsiveness and Customer Satisfaction}

Al-Fawzan (2005) witnessed that responsiveness involves customers continuously being educated when the service is done, workers continuously respond to customer's needs; workers serving customers without delay are portion of the responsive factor. Customers get satisfied when banks provide individual attention and the employees are paying attention to problems experienced by customers regarding safety in transaction (Kumar et al., 2009). Parasuraman et al., (1988) viewed that willingness or readiness of employees to provide the required customer service without any inconvenience at any time will strongly influence the level of customer satisfaction. The above arguments will lead to the development of the following hypothesis:

H3: Responsiveness has a significant positive effect on customers' satisfaction.

\subsubsection{Relationship between Assurance and Customer Satisfaction}

Assurance is defined as the information and great conduct or kindness of employees (Van Iwaarden et al., 2003). Advance, it is additionally characterized as the ability of workers with the assistance of the knowledge possessed to motivate believe and certainly will strongly strike the level of customer satisfaction (Parasuraman et al., 1988). In banking services provided to the customer, assurance means giving financial related help in a neighborly and inviting way, ease in availability of account details, comfort or convenience inside the bank, a well experienced and professional management team and will have favorable outcomes on customer satisfaction (Sadek et al., 2010). The above arguments will lead to the development of the following hypothesis:

H4: Assurance will have a significant impact on Customer Satisfaction.

\subsubsection{The relationship between Empathy and customer satisfaction}

The more the service supplier gets things from the client's point of view, the better. The central idea of empathy is to get the needs of the client and offer person consideration. Client and workers interactions are resounded through the empathy dimensions (Brady and Croning, 2001). Empathy shows the commitment to the client which only the workers are capable of showing. Siddiqi (2011) outlined that the bank customers needed a high level of interaction with the individuals of staff at the bank and they expected personalized service from the individuals of staff. The bank clients also need front line individuals of workers who are competent of comprehending their needs. The study suggested that empathy has a great positive correlation with client satisfaction. Ladhari (2009) also recognized that empathy is the leading predictor of customer satisfaction. These arguments will lead to the development of the following hypothesis:

H5: Empathy has a significant positive effect on customers' satisfaction.

\section{Research Methodology \\ 3.1 Research Design}

This study is an exploratory research type. In order to suit for the collection of the required information from a larger sample and make the analysis easier, the researcher used a quantitative technique by incorporating a qualitative idea in a structured questionnaire. Among the quantitative techniques, survey method is selected. According to Zikmund (2000) survey is defined as "a research technique in which information is gathered from a sample of people by use of a questionnaire." Survey research is of a generalization approach, and hence this study has explored and generalized the assessment of service quality and its effects on the level of customer satisfaction in bank service.

\subsection{Data type and Data Collection Method}

The researcher used primary data that were collected via survey. A set of questionnaire was distributed to customers of Commercial Bank of Ethiopia, Mekelle branch and the primary data were gathered via a questionnaire. The questionnaire was designed in close- ended questions. Close end questions were structured questions which require less effort to complete and it is easy for analysis. The questionnaire has three sections. The first part is intended to solicit data on demographic characteristics. The Second one is designed to address data on perceptions of customer regarding service quality delivery of the bank and the third part of the questionnaire is to evaluate the items/variables on 5 points Likert scale, Likert (1932). This range $1=$ strong disagree, $2=$ disagree, $3=$ neutral, $4=$ 
agree, $5=$ strongly agree. Most of the questionnaire was adapted from previous researchers with a little or no customization i.e. from Parasuraman et. al, (1988) and some of it was developed by the researcher.

\subsection{Sample Design}

The population frame for the study is taken on the basis of customers served daily. Based on the information obtained from the accountants of the bank, the number of customers served on a daily basis is about 300 on average. Therefore, the sample for this study was 300 customers. To avoid sampling bias and errors, the researcher was gathered the data on four days of the week, i.e. Monday, Tuesday, Thursday and Saturday.

In this study, Quota sampling techniques was used. The bank classifies its customers into three groups i.e. saving accounts, current accounts and local transfer. The researcher has considered only saving and current accounts because of time limitation. The number of customers that are served daily on the two categories, saving and current accounts is 200 and 100 respectively. The researcher contacted with the customers/respondents based on convenience sampling.

\subsection{Method of Data Analysis}

The collected data was coded and entered in to a statistical package for social science (SPSS) version 16 for analysis purpose. The data analysis techniques that were used in this study are reliability test, descriptive analysis, Pearson correlation, ordered logit regression and factor analysis. Demographic characteristics of respondents like background, gender, age, level of education, type of account, and other general related information such as telling to others about the bank service, frequency of contact with bank, alternatively other bank service uses and mobility of customers from the bank to other banks were described using descriptive statistics like mean, frequency and standard deviation.

\section{Pearson Correlation}

Pearson correlation was used to examine the relationship between study variables. Correlation coefficient varies between +1 and -1 . While a coefficient of +1 indicates perfect positive correlation, -1 shows negative perfect correlation. A correlation coefficient of 0 , however, designates that there is no correlation between the variables (Iversion and Gergen, 1997).

$\operatorname{Correl}(X, Y)=\sum\left(\mathbf{x}-\mathbf{x}^{\prime}\right)\left(\mathbf{y}^{\left.-y^{\prime}\right)} /\right.$ Square root of or $\sqrt{ }\left[\sum\left(\mathbf{x}-\mathbf{x}^{\prime}\right)^{2} \sum\left(\mathbf{y}^{2}-\mathbf{y}^{\prime}\right)^{2}\right]$

Reliability Test

Where $\mathrm{X}^{\prime}$ and $\mathrm{Y}^{\prime}$ are the sampling means

Reliability is the consistency test of a measurement or measuring instruments. The inter reliability of variables were tested using Cronbach's alpha. The Cronbach's alpha Value which are equal or greater than suggested criterion 0.7 is accepted, otherwise rejected (Hair et. al, 2005).

\subsection{Description of Variables \\ Dependent variables}

Customer satisfaction is the dependent variable in this research. It is defined as the manner in which customers of service organization, like banking industries are very happy with the financial delivery of the bank. When the customers of the bank are satisfied or delighted, the bank can get a good reputation.

\section{Independent Variables}

Reliability: the ability to deliver the promised service as per the needs customer at the required time. It is also the consistency of the relationship the customers have with the employees of the bank.

Responsiveness: the Willingness to help customers and provide prompt service. Keeping customers waiting, particularly for no apparent reason, create unnecessary negative perceptions of quality. If a service is not delivered properly, employees of the organization should be trained to resolve the problem. The enthusiasm of the managers and employees to assist the customers of the organization and how much the employees of the organization are ready to offer good service for the customers leads to customer satisfaction.

Assurance: includes awareness and civility of employees and their ability to inspire trust, treat customers. It is the competence to perform the service, politeness and respect for the customer, effective communication with the customers and the general attitude that the server has the customer's best interests at heart. If the employees and managers of the organization have confidence, persistently courteous and knowledgeable, customers will be satisfied.

Empathy: the provision of thoughtful and individualized consideration that the organization provides to its customers. Employees of the bank industry should know the needs of the customers and use cooperative behavior to attract customers.

Tangibles: It includes physical facilities, equipment and appearance of workers and the suitable working environment i.e. comfortable for the employees. When the bank has good working hours, updated equipments, enough facilities and professional employees, customers will be happy with the delivery of the service. 


\subsection{Ordered Logit Model Specification}

With regard to the objectives of this study, an ordered logit explanatory model was estimated based on the following specification (Verbeek, 2004).

$Z_{i}=\beta 1 X 1_{i}+\beta 2 X 2_{i}+\beta 2 X 2_{i}+\beta 3 X 3_{i+} \beta 4 X 4_{i}+\beta 5 X 5_{i}+\varepsilon_{i}$

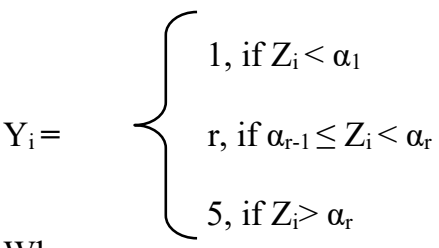

Where:

$\mathrm{Z}_{\mathrm{i}}$ is an unobserved, latent, continuous dependent variable $\beta_{1}$ is a coefficient that relate tangibility to customer satisfaction $\beta_{2}$ is a coefficient that relate reliability to customer satisfaction $\beta_{3}$ is a coefficient that relate responsiveness to customer satisfaction $\beta_{4}$ is a coefficient that relate assurance to customer satisfaction $\beta_{5}$ is a coefficient that relate empathy to customer satisfaction $\mathrm{X}_{1}$ represents observed value of tangibility $\mathrm{X}_{2}$ represents observed value of reliability $\mathrm{X}_{3}$ represents observed value of responsiveness $\mathrm{X}_{4}$ represents observed value of assurance $\mathrm{X}_{5}$ represents observed value of empathy $\varepsilon_{\mathrm{i}}$ is the disturbance term $Y_{i}$ denotes customer satisfaction as a function of $Z_{i}, Y_{i}$ particularly takes values from 1 to 5 $r$ represents real numbers from 2 to 4 $\alpha_{\mathrm{r}}$ represents cut points ranging from $\alpha_{1}$ to $\alpha_{4}$ $Y_{\mathrm{i}}$ as a function of $Z_{\mathrm{i}}$ is illustrated in the following figure.

Figure. 3.1 relationship of dependent variable with the latent variable

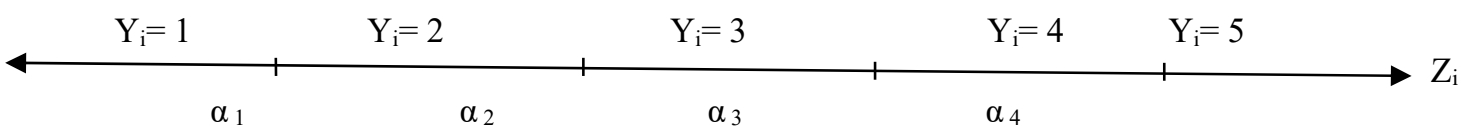

\section{Findings and Discussion \\ 4.1 Introduction}

Once data has been collected through the survey questionnaire, it was coded and entered into SPSS for the purpose of analysis. The objective of this chapter, therefore, is to present the results of the analysis. The first section of this chapter contains the demographic characteristics and analysis of general questions for customer service in the bank. The second section contains the effect of service quality dimensions on customer satisfaction. Finally, the results of hypotheses testing are presented. Therefore, assessment of service quality and its impact on customer satisfaction is examined.

\subsection{Profile of the Respondents}

In the scope of the main survey, 300 questionnaires were distributed to customers of the bank on the six days of the week i.e. Monday, Tuesday, Wednesday, Thursday, Friday and Saturday. On these six days, 300 questionnaires were collected. Out of 300 questionnaires returned, 275 (91.67\%) were considered to be valid and usable.The invalid ones caused by the failure to answer all the questions required. The data collected from 275 respondents were later used to analyze the service quality delivery of the bank. The source of information is designed from a sample of 300 customers of the bank and of which 200 are savings account holders and the rest 100 are current account holders. Hence the analysis is made based on information obtained from the questionnaire filled by respondents.

Moreover, the responses of the subjects are presented, analyzed and interpreted using SPSS version 21, reliability tests and other descriptive statistics. The researcher believed that the information collected from the respondents is reliable and accurate as most of the respondents are familiar with the bank. Thus, based on the responses obtained from the sample respondents, the analysis and interpretation of data are presented as given below. 


\subsection{Demographic Characteristics of the Respondents}

This includes respondents' age group, gender category, level of education, type of account, frequency of customer contact, recommending to others, and alternative service of other bank and shifting of customers to other bank. This helps to understand that from which age group, gender category, level of education and type of account, the data are obtained.

\begin{tabular}{|c|c|c|c|c|}
\hline & & Frequency & percent & cumulative percent \\
\hline \multirow{3}{*}{ Gender } & Male & 189 & 68.73 & 68.73 \\
\hline & Female & 86 & 31.27 & 100 \\
\hline & Total & 275 & 100 & \\
\hline \multirow[t]{5}{*}{ Age } & $21 \&$ below & 68 & 24.73 & 24.73 \\
\hline & $22-35$ & 138 & 50.18 & 74.91 \\
\hline & $36-45$ & 51 & 18.55 & 93.46 \\
\hline & $46 \&$ above & 18 & 6.55 & 100 \\
\hline & Total & 275 & 100 & \\
\hline \multirow[t]{5}{*}{ Level of Education } & Certificate \& below & 53 & 19.27 & 19.27 \\
\hline & Diploma & 83 & 30.18 & 49.45 \\
\hline & Degree & 131 & 47.64 & 97.09 \\
\hline & Masters \& above & 8 & 2.91 & 100 \\
\hline & Total & 275 & 100 & \\
\hline \multirow[t]{3}{*}{ Type of Account } & Current & 98 & 35.64 & 35.64 \\
\hline & Saving & 177 & 64.36 & 100 \\
\hline & Total & 275 & 100 & \\
\hline
\end{tabular}

Table 4.1 summarizes the overall information about the background of the respondents. As it can be seen from the gender the above Table 1: $189,(68.73 \%)$ of the respondents are male and the rest $86,(31.27 \%)$ are female. This revealed that the proportion of female is low on customers of the bank. With regard to the respondents age $138(50.18 \%)$ are in the age of $22-35$ years; $68,(24.73 \%)$ are aged within 21 and below years; $51(18.55 \%)$ are in the age of 36-45 years, and the rest $18(6.55 \%)$ are 46 and above years old. With reference to educational level of the respondents below, $131(47.64 \%)$ of the respondents are bachelor degree holders, $83(30.18 \%)$ of the respondents are diploma holders, $53(19.27 \%)$ have certificate and the rest $8(2.91 \%)$ respondents are masters and above degree holders. Regarding, the type of account the customers/respondents they hold, 177 (64.36\%) respondents are savings account holders. The rest 98 (35.64\%) respondents are current account holders.

Table 4.2: Distribution of respondents on recommending to others, frequency of contact, use of other bank's service, and mobility of customers to other banks.

\begin{tabular}{|c|c|c|c|c|}
\hline & & $\begin{array}{l}\text { Frequenc } \\
\mathbf{y}\end{array}$ & $\begin{array}{l}\text { percen } \\
t\end{array}$ & cumulative percent \\
\hline \multirow[t]{3}{*}{ Recommending bank services to friends } & No & 160 & 58.18 & 58.18 \\
\hline & Yes & 115 & 41.82 & 100 \\
\hline & Total & 275 & 100 & \\
\hline \multirow[t]{5}{*}{ Frequency of customer contact with bank } & One or less & 115 & 41.82 & 41.82 \\
\hline & 2-4 times & 101 & 36.73 & 78.55 \\
\hline & $5-8$ times & 38 & 13.82 & 92.37 \\
\hline & 9 or more times & 21 & 7.64 & 100 \\
\hline & Total & 275 & 100 & \\
\hline \multirow[t]{3}{*}{ Use of alternative bank service } & No & 132 & 47.64 & 47.64 \\
\hline & Yes & 144 & 52.36 & 100 \\
\hline & Total & 275 & 100 & \\
\hline \multirow[t]{3}{*}{ Shifting to other bank } & No & 41 & 14.91 & 14.91 \\
\hline & Yes & 234 & 85.09 & 100 \\
\hline & Total & 275 & 100 & \\
\hline
\end{tabular}

Table 4.2 presents the feedback of respondents about recommending bank service to friends, relatives; frequency of customers flowing to the bank monthly on average; whether they use other alternative bank services and the mobility of customers from the bank to other banks if they are not satisfied or does not exceed their expectations. Accordingly, $160(58.18 \%)$ of the respondents do not recommend to their friends or relatives about 
the service of the bank; the rest $115(41.82 \%)$ of the respondents were recommending the actual service performance of the bank to their friends, relatives and others to become customers of the bank. Hence, most of the customers of the bank are telling the actual service delivery of the bank to their friends and other customers of other bank to be customers of Commercial Bank of Ethiopia. This helps the bank to have more new potential customers.

Majority of the respondents $115(41.82 \%)$ come to the bank for a service one or less time on average in a month. While $101(36.73 \%)$ of the respondents do business in 2-4 times, those respondents that contact the bank 5-8 times on average in month accounts $38(13.82 \%)$, while $21(7.64 \%)$ of the respondents use to come 9 or more times on average in a month. With regard to the use of other alternative service bank; $143(52 \%)$ of the respondents are using service of any other banks. And the rest $132(48 \%)$ of the respondents are not use the service of other banks. i.e. they are only customers of commercial bank of Ethiopia. With regard to, the shifting or mobility of customers from the bank, if they are happy or their expectation is met: in this, $234(85.09 \%)$ of the respondents are willing to shifting from the bank to other banks if the bank offers unsatisfactory customer service and if their expectation is not met. Moreover, 41 (14.91\%) of the respondents, do not to shift even if they are not satisfied with the service of the bank. This is because of believe that they assume that other banks are not offering services that exceed the service of commercial bank and they assume all banks are the same on the delivery of customer services.

\begin{tabular}{|l|l|l|l|}
$\begin{array}{l}\text { Table 4.3: Summary of the Descriptive Statistics of the study variables } \\
\text { Variables }\end{array}$ & Observation & Mean & Std. Dev. \\
\hline Tangibility & 275 & 4.03 & 0.95 \\
\hline Reliability & 275 & 3.99 & 0.99 \\
\hline Responsiveness & 275 & 4.03 & 1.01 \\
\hline Assurance & 275 & 3.97 & 1.04 \\
\hline Empathy & 275 & 4.00 & 1.08 \\
\hline Customer satisfaction & 275 & 4.04 & 1.16 \\
\hline
\end{tabular}

Table 4.3 shows the mean and standard deviation for all measures ( 22 items) for service quality dimensions and 4 items of customer satisfaction. The mean value of all service quality dimensions (tangible, reliability, responsiveness, assurance and empathy) ranges between "3.97" to "4.03" which is in the scaling of agree and strongly agree level. With reference to service quality dimensions, the mean value of tangibility $(\mathrm{M}=4.03)$ and responsiveness (4.03) are relatively the highest and assurance have relatively the lowest mean value $(\mathrm{M}=3.97)$. This indicates that the customers' perceived service quality on tangibility and reliability is high. As the mean values of all service quality dimensions are almost 4, customers of the bank are almost satisfied or agreed with the five service quality dimensions. But, they are not strongly agreed or highly satisfied. Among the five service quality dimensions, the highest standard deviation correspondences to empathy (1.08). On the other hand, the lowest standard deviation correspondences to tangibility i.e. 0.95. This indicates that indicates that consistency in tangibility is higher than reliability, responsiveness, assurance and empathy. The Mean value of customer satisfaction is 4.04, which indicates that on average, customer's response to the level of satisfaction is agreed. Generally, the degree of service quality dimensions and the level of customer satisfaction of the bank are on the range of satisfactory or agree scale.

\subsection{Effects of Service Quality Dimensions on Customer Satisfaction 4.4.1 Reliability Test of the Items}

Before analyzing the data collected, the researcher has conducted the scale's reliability test for the main items of the questionnaire. The reliability of the scale containing 22 items used to measure service quality dimensions toward customer satisfaction in commercial bank of Ethiopia was tested using Cronbach's Alpha. According to Hair et. al, (2005) a reliability coefficient 0.7 or higher is acceptable. Table 4.4 shows the reliability coefficient for all items is above 0.7 and the overall reliability test for the items is $83.5 \%$ so, the data are reliable or acceptable. Table 4.4: Reliability Test

\begin{tabular}{|r|r|r|}
\hline \multicolumn{1}{|c|}{ Cronbach's alpha } & Cronbach's alpha based on standardized item & \multicolumn{1}{c|}{ number of items } \\
\hline $\mathbf{0 . 8 3 5}$ & 0.836 & 22 \\
\hline
\end{tabular}

\section{Correlation analysis of the variables}

The following Table 4.5 shows the relation among each of the dimensions of service quality with customer satisfaction. The relationship between tangibility and customer satisfaction is $(r=0.50, p=0.000)$. This indicates that tangibility of the bank for customer services and the level of customer satisfaction are strongly and positively correlated. This finding is consistent with Newman (2001).He found that tangibles surpass customers' expectations in banks services.

The relationship between reliability and customer satisfaction $(r=0.541, p=0.000)$, this indicates that reliability and customer satisfaction have a strong positive relationship. This indicates that reliability of the bank 
for customer services and the level of customer satisfaction are strongly and positively correlated. This findings is consistent with Lam (2002), have been ranked as the first or second very important characteristics of service quality dimensions which affect customer satisfaction.

The relationship between responsiveness and customer satisfaction $(r=0.56, p=.0 .000)$ which indicates a strong positive relationship. This indicates that responsiveness of the bank for customer services and the level of customer satisfaction are strongly and positively correlated.

The relationship between assurance and customer satisfaction $(\mathrm{r}=0.51, \mathrm{p}=0.000)$ indicates a strong relationship. This indicates that assurance of the bank for customer services and the level of customer satisfaction are strong and positively correlated. This result is similar with the findings of Newman (2001) which is used assurance to staff capability in providing a knowledgeable, confidential service, well-mannered service, and staff ability to provide sociable service.

The relationship between empathy and customer satisfaction $(r=0.552, p=0.000)$ which reveals that a strong positive relationship. This indicates that empathy of the bank for customer services and the level of customer satisfaction are strongly and positively correlated. Since the relationship between all service quality dimensions and customer satisfaction in the bank, is direct and ranging from 0.50 to 0.56 which is in the scale of moderate and strongly positive correlation, the bank's managers and employees should take a good position on the five dimensions to satisfy its customers.

Generally, the relationship between the service quality dimensions (tangibility, reliability, responsiveness, assurance and empathy) and customer satisfaction is direct or positive.

Table 4.5: Pearson Correlations Analysis the Service quality dimensions and customer satisfaction.

\begin{tabular}{|c|c|c|c|c|c|c|}
\hline & $\begin{array}{l}\text { Customer } \\
\text { satisfaction }\end{array}$ & tangibility & reliability & responsiveness & assurance & empathy \\
\hline Customer satisfaction & 1 & & & & & \\
\hline tangibility & $0.50^{*}$ & 1 & & & & \\
\hline reliability & $0.541^{*}$ & $0.352 *$ & 1 & & & \\
\hline responsiveness & $0.560 *$ & $0.396^{*}$ & $0.437 *$ & 1 & & \\
\hline assurance & $0.51 *$ & $0.248^{*}$ & $0.414^{*}$ & $0.391 *$ & 1 & \\
\hline empathy & $0.552 *$ & $0.322 *$ & $0.511^{*}$ & $0.418^{*}$ & $0.343 * *$ & 1 \\
\hline
\end{tabular}

* Correlation is significant at the 0.01 level (2-tailed). $\mathrm{N}=275$

\subsection{Ordered Logit Model Regression Analysis}

Ordered logit regression was held with customer satisfaction as dependent variable and five other independent variables i.e. tangibility, reliability, responsiveness, assurance and empathy as determinant factors for the level of customer satisfaction in Commercial Bank of Ethiopia, Mekelle branch. As customer satisfaction is measured on a 5 point likert scale, it is discrete variable taking 5 categorical values. There is an increment in its value as it goes from $1=$ strongly disagree to $5=$ strongly agree which makes its value ordered. Hence, an ordered logit regression model is estimated based on the categorical nature of the dependent variable. Based on the result from the regression analysis, the likelihood of having higher customer satisfaction can be predicted as a function of the five service quality dimensions i.e. tangibility, reliability, responsiveness, assurance and empathy.

Before proceeding to the interpretation of the result of the regression analysis, it was checked whether assumptions to use ordered logit model was met or not. One of the assumptions underlying ordinal logistic regression is proportional odds or the parallel regression assumption. It assumes that coefficients that describe the relationship between, say, the lowest versus all higher categories of the dependent variable are the same as those that describe the relationship between the next lowest category and all higher categories etc. The null hypothesis states that there is no difference in the coefficients between models (there is only one model). Significance of the Chi-Square statistic of the general model is a condition to reject the null hypothesis. As it can be seen from table 4.6, the Chi-Square statistic is not significant at $5 \%$ level of significance $(0.206>0.05)$. Thus, null hypothesis is accepted and parallel regression assumption is met. The parallel line test for the model is given in the table below. Table 4.6: Test of Parallel Lines ${ }^{\mathrm{c}}$

\begin{tabular}{|c|c|c|c|c|}
\hline Model & -2 Log Likelihood & Chi-Square & $\mathrm{df}$ & Sig. \\
\hline Null Hypothesis & 292.696 & & & \\
\hline General & 273.514 & 19.181 & 15 & .206 \\
\hline
\end{tabular}

$\mathrm{C}=$ Link function: Complementary Log-log.

As it has been found that ordered logit regression model assumption of proportional odds is met, overall model fitness test comes next. Table 4.7 shows the overall model fitting information. The null hypothesis states that all of the regression coefficients in the model are equal to zero. The significance of the Chi-Square statistic of the final model $(0.000<0.05)$ indicates rejection of null hypothesis and inference of overall model fitness. In other words, this indicates that the model gives a significant improvement over the intercept-only model. 
Table 4.7: Overall model fitting information

\begin{tabular}{|l|r|r|r|r|}
\hline Model & \multicolumn{1}{|c|}{-2 Log Likelihood } & Chi-Square & df & Sig. \\
\hline Intercept Only & 612.874 & & & \\
\hline Final & 292.696 & 320.178 & 5 & .000 \\
\hline
\end{tabular}

Link function: Complementary Log-log

Model fitting information shows overall model fitness. However, it cannot explain the degree of goodness of fit. Indeed, Table 4.8 presents goodness of fit of the model. Pearson and Deviance goodness of fit measures are calculated based on expected and observed frequencies. A good fit, therefore, is to mean that expected and observed values are found to be similar. A large observed significance level shows a good data and model fit. The observed significance level of the goodness of fit measures of this model, as it can be evidenced from table 4.8, are larger indicating that the model fits with the data well.

Table 4.8: Pearson and Deviance Goodness of fit measures

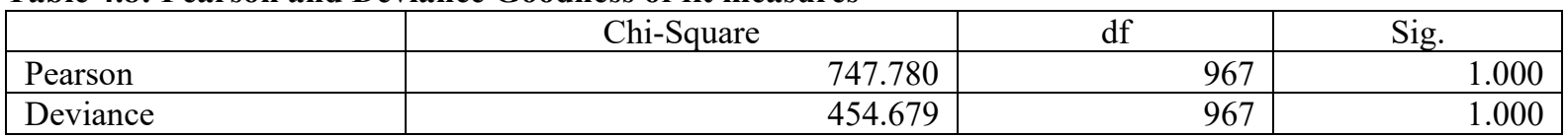

Link function: Complementary Log-log.

Pseudo R-square statistics are used to measure the strength of the association between dependent and predictor variables. However, since their interpretation is not straight forward, they are not as useful as the R-square statistic in linear regression. As it can be evidenced from Table 4.9 below, the pseudo R-square measures of this model are very well.

Table 4.9: Pseudo R-square measures of the model

Pseudo R-square

\begin{tabular}{|l|r|}
\hline Cox and Snell & 0.688 \\
\hline Nagelkerke & 0.771 \\
\hline McFadden & 0.522 \\
\hline
\end{tabular}

Link function: Complementary Log-log.

Having tested the model with several tests and showed its overall fitness now follows interpretation of the result of the regression. Table 4.10 presents parameter estimates of the result when customer satisfaction is regressed on tangibility, reliability, responsiveness, assurance and empathy with the help of SPSS PLUM ordinal regression. The threshold values are estimated cut points between the values of the dependent variable and are used in the calculations of predicted values. Their values do not depend on independent variables; simply they are like the intercept in a linear regression.

Table 4.10: Regression Model Summery of the dependent and independent variables Parameter Estimates

\begin{tabular}{|ll|r|r|r|r|r|r|r|}
\hline & & & & & & \multicolumn{3}{|c|}{$95 \%$ Confidence Interval } \\
\cline { 6 - 8 } & & Estimate & Error & Wald & Df & \multicolumn{1}{|c|}{ Sig. } & Lower Bound & Upper Bound \\
\hline Threshold & {$[\mathrm{cs}=1.00]$} & 6.106 & .951 & 41.211 & 1 & .000 & 4.242 & 7.971 \\
& {$[\mathrm{cs}=2.00]$} & 7.790 & .875 & 79.281 & 1 & .000 & 6.075 & 9.505 \\
& {$[\mathrm{cs}=3.00]$} & 9.655 & .962 & 100.792 & 1 & .000 & 7.770 & 11.540 \\
& {$[\mathrm{cs}=4.00]$} & 12.066 & 1.061 & 129.259 & 1 & .000 & 9.986 & 14.146 \\
Location & tan & .401 & .152 & 6.936 & 1 & .008 & .103 & .700 \\
& rel & .417 & .171 & 5.922 & 1 & .015 & .081 & .753 \\
& res & .568 & .152 & 13.933 & 1 & .000 & .270 & .866 \\
& ass & .842 & .159 & 28.064 & 1 & .000 & .530 & 1.153 \\
& emp & .727 & .159 & 20.946 & 1 & .000 & .415 & 1.038 \\
\hline
\end{tabular}

Link function: Complementary Log-log

Dependent variable: $\mathrm{cs}=$ Customer satisfaction

Independent variables: $\tan =$ tangibility, rel $=$ reliability, res $=$ responsiveness, ass $=$ assurance and emp $=\mathrm{empathy}$

\subsection{Interpretation of the Estimates or coefficients}

The ordered logit regression coefficients, Standard interpretation of the ordered logit coefficient is that for a one unit increase in the predictor (independent variable) the response variable (independent variable) is expected to change by its respective regression coefficient in the ordered logit odds while the other variables in the model are held constant.

Tangibility (tan)- This is the ordered logit odds estimate for one unit increase in tangibility values on the expected 
level of customer satisfaction given the other variables are held constant in the model. If tangibility of the bank is to increase by one unit, the ordered logit odds of being in a higher customer satisfaction category would increase by 0.401 while the other variables in the model are held constant.

Reliability (rel)- A one unit increase in reliability of the bank would result in a 0.417 units increase in the ordered log-odds of being in a higher customer satisfaction level category while other variable in the model are held constant

Responsiveness (res)- A one unit increase in responsiveness of the bank would result in a 0.568 units increase in the ordered log-odds of being in a higher customer satisfaction level category while other variable in the model are held constant

Assurance (ass)- A one unit increase in responsiveness of the bank would result in a 0.842 units increase in the ordered log-odds of being in a higher customer satisfaction level category while other variable in the model are held constant.

Empathy (emp)- A one unit increase in empathy of the bank would result in a 0.727 units increase in the ordered log-odds of being in a higher customer satisfaction level category while other variable in the model are held constant.

The Wald test statistic for the predictor tangibility is 6.936 with associated p-value of 0.000 which is quiet significant at $1 \%$ significance level. Thus, the null hypothesis that states the predictor's regression coefficient is zero, and is rejected and hence, it can be inferred that tangibility is statistically significant predictor of customer satisfaction. Similarly, the Wald test statistic for reliability is 5.922 with associated p-value of 0.000 which is quiet significant at 1\% significance level inferring that reliability is statistically significant predictor of customer satisfaction. The Wald rest statistics for responsiveness is 13.933 with associated p-value of 0.000 which is quiet significant at $1 \%$ significance level inferring that responsiveness is statistically significant predictor of customer satisfaction. The Wald test statistic for assurance is 28.064 with associated p-value of $0.015,(0.015<0.05)$. The test is significant at 5\% significance level; which is significant at $5 \%$ inferring that assurance is statistically significant predictor of customer satisfaction. And the Wald rest statistics for empathy is 20.946 with associated pvalue of 0.000 which is quiet significant at $1 \%$ significance level inferring that empathy is statistically significant predictor of customer satisfaction. The positive coefficients of all tangibility, reliability, responsiveness, assurance and empathy imply that the likelihood of having higher customer satisfaction and increase the perceived service quality of the clients towards commercial bank of Ethiopia, Mekelle branch. The higher coefficient value of assurance as compared to the others implies that predicting power of assurance is the best of all. This result confront with that of the correlation analysis which revealed that relationship between assurance and customer satisfaction is stronger comparatively. The next higher coefficient value is found in empathy, which indicates a strong relationship between empathy and customer satisfaction. The coefficient value of responsiveness which also reveals strongly predicts level of customer satisfaction. The coefficient values of reliability and tangibility are 0.401 and 0.417 respectively, which indicate that positively and statistically predicting customer satisfaction.

The observed ordinal variable $\mathrm{Y}$ is a function of the unmeasured continuous latent variable $\mathrm{Z}$ which has four threshold points. The association between $\mathrm{Y}$ and $\mathrm{Z}$ is explained using the following example as follow.

Latent variables $(\mathbf{Z i})$ : is an unobserved, continuous dependent variable

$\mathrm{Y}_{\mathrm{i}}$ denotes customer satisfaction as a function of $\mathrm{Z}_{\mathrm{i}}, \mathrm{Y}_{\mathrm{i}}$ particularly takes values from 1 to 5

$Z=0.401 * \tan _{i}+.0 .417 *$ reli $_{i}+0.568 *$ resi $_{i}+0.842 * \operatorname{ass}_{i}+0.727 * \mathrm{emp}_{i}+\varepsilon_{i}$,

From the table of parameter estimates, the latent variable $\mathrm{Z}$ is estimated by: $\mathrm{Z}_{\mathrm{i}}=0.401 * \tan _{\mathrm{i}}+.0 .417 * \mathrm{rel}_{\mathrm{i}}+0.568 *$ res $_{i}+0.842 *$ ass $_{i}+0.727 * \mathrm{emp}_{\mathrm{i}}+\varepsilon_{\mathrm{i}}$, the disturbance term $\varepsilon$ has normal distribution with mean value of zero (Gujarati, 2004) and is not included in the calculation. Therefore, $Z_{i}=0.401 * \tan _{i}+.0 .417 * r^{2} l_{i}+0.568 * \operatorname{res}_{i}+$ $0.842 * \mathrm{ass}_{\mathrm{i}}+0.727 * \mathrm{emp}_{\mathrm{i}}$. Considering mean values of the observations $\tan =4.03$, rel $=3.99$, res $=4.03$, ass $=3.97$ and $\mathrm{emp}=4.00, Z_{\text {mean }}=(0.401 * 4.03)+(0.417 * 3.99)+(0.568 * 4.03)+(0.842 * 3.97)+(0.727 * 4.00)=11.82$

Based on the value of $Z$ probability of each response values of $Y$ can be calculated as follows.

$\left.\mathrm{P}(\mathrm{Y}=1)=1 /\left(1+\exp \left(\mathrm{Z}-\alpha_{1}\right)\right)=1 /(1+\exp (11.82-6.106))\right)=0.0033=0.33 \%$,

$\mathrm{P}(\mathrm{Y}=2)=1 /\left(1+\exp \left(\mathrm{Z}-\alpha_{2}\right)\right)-\left(1 /\left(1+\exp \left(\mathrm{Z}-\alpha_{1}\right)\right)\right)=1 /(1+\exp (11.82-7.790))-0.0033=0.0142=1.42 \%$

$\mathrm{P}(\mathrm{Y}=3)=1 /\left(1+\exp \left(Z-\alpha_{3}\right)\right)-\left(1 /\left(1+\exp \left(Z-\alpha_{2}\right)\right)\right)=1 /(1+\exp (11.82-9.655))-0.0142=0.0887=8.87 \%$

$\mathrm{P}(\mathrm{Y}=4)=1 /\left(1+\exp \left(\mathrm{Z}-\alpha_{4}\right)\right)-\left(1 /\left(1+\exp \left(\mathrm{Z}-\alpha_{3}\right)\right)\right)=1 /(1+\exp (11.82-12.066))-0.0887=0.4725=47.25 \%$

$\mathrm{P}(\mathrm{Y}=5)=1-\left(1 /\left(1+\exp \left(\mathrm{Z}-\alpha_{4}\right)\right)\right)=1-0.5612=0.4388=43.88 \%$

$\mathrm{P}(\mathrm{Y}=1)=0.33 \%$ indicates the probability that customers of the bank are strongly dissatisfied or strongly disagree with the service delivery of the bank.

$\mathrm{P}(\mathrm{Y}=2)=1.42 \%$ indicates the probability that customers of the bank are dissatisfied or disagree with the service delivery of the bank.

$\mathrm{P}(\mathrm{Y}=3)=8.87 \%$ indicates the probability that customers of the bank are strongly neutral with the service delivery of the bank, which is between disagree and agree.

$\mathrm{P}(\mathrm{Y}=4)=47.25 \%$ indicates the probability that customers of the bank are satisfied or agree with the service delivery of the bank. 
$\mathrm{P}(\mathrm{Y}=5)=43.88 \%$ indicates the probability that customers of the bank are strongly satisfied or strongly agree with the service delivery of the bank.

Where:

exp represents exponent, it is to mean e the power of figure indicated in the bracket $(\mathrm{e}=2.71)$

$\mathrm{P}(\mathrm{Y}=1)$ : probability of $\mathrm{y}=1$ and others can be understood similarly.

$\alpha_{\mathrm{r}}$ represents cut points ranging from $\alpha_{1}$ to $\alpha_{4}$

The value of $Z$ which is 11.82 is greater than $\alpha_{3}=9.655$ and less than $\alpha_{4}=12.066$ (i.e. $9.655<Z<12.066$ ) implying that $\mathrm{Y}=4$. Moreover, among the 5 possible response values, probability of $\mathrm{Y}=4$ being $47.25 \%$ is the largest probability. The observed mean value of customer satisfaction is 4.04 which will be 4 when rounded, thus fitting with the result. Based on the estimated equation of $Z$, it is possible to predict customer satisfaction of customers for particularly specified values of tangibility, reliability, responsiveness, assurance and empathy toward the bank customer service. As the values of tangibility, reliability, responsiveness, assurance and empathy used to calculate the above value of $Z$ are measured mean values of respondents, it can be inferred that their likelihood of considering customer satisfaction level of the clients toward the service quality of the bank is $47.25 \%$ probable.

The position of calculated $\mathrm{Z}$ value in the threshold points is used to identify the most probable response value based on the given values of predictors from which $\mathrm{Z}$ is obtained. Without calculating the probability values it is possible to know the most probable response. Probability then shows how much probable is that response value. The value how much probable is the response is important because, the most probable response is that with highest probability but not the only probable one. Thus, observing the difference of probabilities between the responses may have the influence of changing decisions.

The effect of tangibility, reliability, responsiveness, assurance and empathy on the likelihood probability of customer satisfaction can be seen by computing $\mathrm{Z}$ several times by holding one of the independent variables constant and changing the other variable. For instance, holding tangibility, reliability, responsiveness and empathy at 4.03, 3.99, 4.03 and 4.00 respectively, and changing assurance by the same amount to $4, \mathrm{Z}$ is computed to be 11.84. $9.655<\mathrm{Z}=11.84<12.066$ implying that $\mathrm{Y}=4$ which is equivalent to previous example. However, while the probability of $\mathrm{Y}=4$ decreased to $46.91 \%$, and probability of $\mathrm{Y}=5$ increased to $44.37 \%$. And the overall probability of having higher likelihood of customer satisfaction is increased by $0.15 \%$.

Similarly, holding tangibility, responsiveness, assurance and empathy at 3.99, 4.03, 3.97 and 4.00 respectively, and changing reliability by the same amount $4.02, \mathrm{Z}$ is computed to be $11.83 .9 .655<\mathrm{Z}=11.83<12.066$ implying that $\mathrm{Y}=4$. While probability of $\mathrm{Y}=4$ increased to $47.10 \%$, probability of $\mathrm{Y}=5$ increased to $44.13 \%$. The overall probability of having higher likelihood of the level of customer satisfaction is increased by $0.10 \%$. While the amount of change in values of the independent variables was the same, the change in overall probability of having higher likelihood of customer satisfaction is different.

Similarly, holding tangibility, reliability, responsiveness and assurance at 4.03, 3.99, 4.03 and 3.97 respectively, and changing empathy by the same amount to $4.03, \mathrm{Z}$ is computed to be $11.84 .9 .655<\mathrm{Z}=11.84<$ 12.066 implying that $\mathrm{Y}=4$. While probability of $\mathrm{Y}=4$ declined to $46.91 \%$, probability of $\mathrm{Y}=5$ increased to $44.37 \%$. The overall probability of having higher likelihood of the level of customer satisfaction is increased by $0.15 \%$. While the amount of change in values of the independent variables was the same, the change in overall probability of having higher likelihood of customer satisfaction is different.

Similarly, holding reliability, responsiveness, assurance and empathy at 3.99, 4.03, 3.97 and 4.00 respectively, and changing tangibility by the same amount to $4.06, \mathrm{Z}$ is computed to be 11.83 . $9.655<\mathrm{Z}=11.83<12.066$ implying that $\mathrm{Y}=4$. While probability of $\mathrm{Y}=4$ decreased to $47.1 \%$, probability of $\mathrm{Y}=5$ increased to $44.13 \%$. The overall probability of having higher likelihood of the level of customer satisfaction is increased by $0.10 \%$. While the amount of change in values of the independent variables was the same, the change in overall probability of having higher likelihood of customer satisfaction is different.

Similarly, holding tangibility, reliability, assurance and empathy at 4.03, 3.99, 3.97 and 4.00 respectively, and changing responsiveness by the same amount to $4.06, \mathrm{Z}$ is computed to be $11.836 .9 .655<\mathrm{Z}=11.836<12.066$ implying that $\mathrm{Y}=4$. While probability of $\mathrm{Y}=4$ decreased to $46.97 \%$, probability of $\mathrm{Y}=5$ increased to $44.27 \%$. The overall probability of having higher likelihood of the level of customer satisfaction is increased by $0.11 \%$. While the amount of change in values of the independent variables was the same, the change in overall probability of having higher likelihood of customer satisfaction is different.

In summary, the comparatively highest coefficient or estimate of assurance( 0.842$)$ and followed by empathy (0.727) from the ordered logit regression equation have resulted in higher change of probability of overall satisfaction of customers when the same change of improvement is considered with the other dimensions of service quality. This implies that if the bank works focusing on improvement of assurance and empathy of the customer service, the likelihood of satisfying its customers will be higher.

\subsection{Results of Hypotheses Testing}

From table 10 ordered logit regression, it can be seen the probable positive effects of independent variables 
(tangibility, reliability, responsiveness, assurance and empathy of the bank) on the response or dependent variable i.e. customer satisfaction. Coefficients of the independent variables, standard errors and Wald test statistics and Pvalue for significant test are given from the ordered logit model. The assessment of hypothesis is based on results in the Table 10 where coefficient or estimate and their significance level are provided. A positive sign of coefficient/estimate/ indicates that probably positive or direct effect of relationship.

\section{H1: Tangibility has significant positive effect on customer satisfaction}

The results of the above Table 10 , the coefficient of tangibles $(0.401, \mathrm{p}=0.000)$, which is positive and their relationship is moderate. Tangibility has a significant positive relationship with customer satisfaction. Hence, the alternative hypothesis (H1) is accepted. The positive coefficient for tangibility means that the likelihood of customer satisfaction does increase with customer services of the bank. Therefore, a one unit increase in tangibility of the bank, probably result a 0.401 unit increase in the level of customer satisfaction while other independent variables in the model are held constant.

\section{H2: Reliability has positive effect on customer satisfaction}

The results of the Table 10 , the coefficient of tangibles $(0.417, p=0.015)$, which is positive and their relationship is moderate. Reliability has a significant positive effect on customer satisfaction at 5 percent significant level. Hence, alternative hypothesis $(\mathrm{H} 2)$ is accepted. The positive coefficient for reliability means that the likelihood of customer satisfaction does increase with customer services of the bank. Thus, a one unit increase in reliability of the bank, probably result a 0.417 units increase in the level of customer satisfaction while other independent variables in the model are held constant.

\section{H3: Responsiveness has a significant positive effect on customer satisfaction}

From the table 10 , the coefficient of responsiveness is $(0.568, \mathrm{p}$-value $=0.000)$ which is positive and strong. Since the coefficient of responsiveness is strong and significant at 1 percent, responsiveness has a positive effect on customer satisfaction. Hence, the alternative hypothesis (H3) is accepted. The positive coefficient for responsiveness means that the likelihood of customer satisfaction does increase with customer services of the bank. Thus, a one unit increase in responsiveness of the bank, probably result a 0.568 units increase in the level of customer satisfaction while other independent variables in the model are held constant.

\section{H4: Assurance has a significant positive effect on customer satisfaction}

From the Table 10 , the coefficient of assurance is $(0.842, \mathrm{p}$-value $=0.000)$ which is positive and strong. Since the coefficient of assurance is strong and significant at 1 percent, assurance has a positive effect on customer satisfaction. Hence, the alternative hypothesis (H4) is accepted. The positive coefficient for assurance means that the likelihood of customer satisfaction does increase with customer services of the bank. Hence, a one units increase in assurance of the bank, probably results a 0.842 units increase in the level of customer satisfaction while other independent variables in the model are held constant.

\section{H5: Empathy has positive effect on customer satisfaction}

From the Table 10 of ordered output, the coefficient of empathy is $(0.727, p$-value $=0.000)$. Since the coefficient reliability positive and significantly strong and significant at 1 percent, empathy has a positive effect on customer satisfaction. Hence, alternative hypothesis (H5) is accepted. The positive coefficient for empathy means that the likelihood of customer satisfaction does increase with customer services of the bank. Therefore, a one unit increases in empathy of the bank, probably results a 0.727 units increase in the level of customer satisfaction while other independent variables in the model are held constant.

\section{Conclusions and Recommendations}

\subsection{Conclusions}

The relationship between the service quality dimensions and customer satisfaction is positive. A positive significant relationship is found between study variables at $1 \%$ level of significance. As it can be understood from correlation coefficients, the strength of their relationship ranges from moderate to strong relationships, i.e. the relationship between tangibility and the customer satisfaction is moderate positive relationship, the relationship between the reliability, responsiveness, assurance and empathy and the customer satisfaction is a positive strong relationship.

Ordered logit regression analysis revealed that all the service quality dimensions contributed significantly to the prediction of the level of customer satisfaction in Commercial Bank of Ethiopia, Mekelle branch. Among all the service quality dimensions, the assurance is found to be highly predictor of perceived service quality with coefficient of 0.842 . This was followed by empathy with a coefficient of 0.727 , and then responsiveness with a coefficient of 0.568 is strong predicting customer satisfaction. Reliability with a coefficient of 0.417 and tangibility with a coefficient of 0.401 are moderate predictors of customer satisfaction. The findings show that there is opportunity for customer satisfaction improvement in commercial Bank of Ethiopia, Mekelle branch.

The tangibility, reliability, responsiveness; assurance and empathy are statistically significant predictors of customer satisfaction. The positive coefficients tangibility, reliability, responsiveness, assurance and empathy infer that the likelihood of having higher customer satisfaction for commercial bank customer service is increasing with 
the tangibility, reliability, responsiveness, assurance and empathy. Based on mean values for independent variables, it is found that the likelihood of respondents considering and intending to perceive the degree of satisfaction is about $47.25 \%$ probable. Hence, service quality dimensions are the primary determinants of customer satisfaction.

\subsection{Recommendation}

Since predicting customer satisfaction on bank service is not simple, the management of the bank exerts a maximum effort, resources to teach, train and develop employees on how to retain existing customers, convince new customers; and on how to achieve competitive advantage through of bank customer service delivery.

\section{References}

Al-Fawzan, M. A. (2005). Assessing Service Quality in a Bank. Journal of King Saud University, 1, 101-115.

Bahia, K. \& Nantel, J. (2000). A reliable and valid measurement scale for perceived service quality of bank. International Journal of Bank Marketing, 2, 84-91.

Brady, M.K. \& Croning, J.J. (2001). Some new thoughts on conceptualizing perceived service quality: A hierarchical approach. Journal of Marketing, 1, 34-49.

Brady, M. K., \& Robertson, C. J. (2001). Searching for a consensus on the antecedent role of service quality and satisfaction: An exploratory cross-national study. Journal of Business Research, 1, 53-60.

Bolton, R. N., and James, H. D. (1994). Linking Customer Satisfaction to Service Operations and Outcomes, in Service Quality, R. Rust and R. Oliver, eds. Thousand Oaks, CA: Sage Publications, 173-2001.

Eshghi, A., Roy, S., \& Ganguli, S. (2008). Service quality and customer satisfaction: An empirical investigation in mobile Telecommunications service. Marketing Management Journal, 2, 119-144.

Fornell, Claes (1991). A National Customer Satisfaction Barometer: The Swedish Experience' Journal of Marketing, 56, 6-21.

Hair, J., Black, B., Babin, B., Anderson, R. E., \& Tatham, R. L. (2005). Multivariate data analysis. New Jersey: Prentice Hall.

Herington, C., \& Weaven, S. (2009). E-retailing by banks: E-service quality and its importance to customer satisfaction. European Journal of Marketing, 9/10, 1220-1231.

Kaynak, E. \& Kucukemiroglu, O. (1992). Bank and Product Selection: Hong Kong. The International. Journal of Bank Marketing, 10, 3-17.

Kotler, P. \& Keller, K.L. (2012). Marketing management. New Delhi: Dorling Kindersley (India) Pvt. Ltd.

Kumar, M., Kee, F.T., \& Manshor, A.T. (2009). Determining the relative importance of critical factors in delivering service quality of banks: An application of dominance analysis in SERVQUAL model. Managing Service Quality, 2, 211-228.

Ladhari, R. (2009). Assessment of the psychometric properties of SERVQUAL in the banking industry. Journal of Financial Services Marketing, 1, 70-82.

Lai, T. L. (2004). Service quality and perceived value's impact on satisfaction, intention and usage of short message service (SMS). Information Systems Frontiers, 4, 353-368.

Mohamed, H. \& Shirley. L, (2009). Customer Perception on Service: The Case of Qatar. International Journal of Islamic and Middle Eastern Finance and Management, 2(4), 338-350.

Papasolomou-Doukakis, I. (2002).The Role of Employee Development in Customer Relations: Corporate Communications. An International Journal, 1, 62-76.

Parsuraman A., Zeithaml., V. A., \& Berry, L.L. (1988). A multiple item scale for measuring consumer perception of service quality. Journal of Retailing, 1, 12-40.

Sadek, D., Zainal, N., Taher, M. \& Yahya, A. (2010). Service Quality Perceptions between Cooperative and Islamic Banks. American Journal of Economics and Business Administration, 1, 1-5.

Siddiqi, K. O. (2011). Interrelations between Service Qualities Attributes, Customer Satisfaction and Customer Loyalty. International Journal of Business and Management, 3, 12-36.

Spreng, Richard, A., Robert, D., \& Mackoy. (1996). An Empirical Examination of a Model of Perceived Service Quality and Satisfaction. Journal of Retailing, 2, 201-214.

Van Iwaarden, J., van der Wiele, T., Ball, L., \& Millen, R. (2003). Applying SERVQUAL to web sites: An exploratory study. International Journal of Quality \& Reliability Management, 8, 919-935.

Verbeek, M. (2004). A Guide to Modern Econometrics. England: John Wiley \& Sons Ltd.

Walfried, L. M., Chris, M. \& Robert, D. W. (2000). Service quality perspective and satisfaction in private banking. Journal of Service Marketing, 3, 244-271.

Yang, Z. \& Fang, X. (2004). Online service quality dimensions and their relationships with satisfaction: A content analysis of customer reviews of securities brokerage services. International Journal of Service Industry Management, 3, 302-326.

Zeithaml, V. (2000). Service quality, profitability and the economic worth of customers: What we know and what we need to learn. Journal of the Academy of Marketing Science, 1, 67- 85. 
Zeithaml, V.A., Parasuraman, A. and Berry, L.L. (1990). Delivering quality service; Balancing customer perceptions and expectations. The Free Press, New York, NY.

Zikmund, W (2000). Business Research Methods. Toronto: The Dryden press Harcourt Brace College Publishers. 